Defining death

\section{Defining death: when physicians and families differ}

\section{J M Appel}

Whether the law should permit individuals to opt out of accepted death standards is a question that must be faced and clarified

W hile media coverage of the Terri Schiavo case in Florida has recently refocused public attention on end of life decision making, another end of life tragedy in Utah has raised equally challenging-and possibly more fundamental—questions about the roles of physicians and families in matters of death. The patient at the centre of this case was Jesse Koochin, a six year old boy suffering from "inoperable and incurable" brain cancer. He had been undergoing care at Primary Children's Medical Center in Salt Lake City since September 15, 2004 when "his tumor pushed his brain stem down through the skull". ${ }^{1}$ Subsequently, two physicians independently determined that the child was "brain dead" and informed his parents that they would order life support removed within twenty four hours. Steve and Gayle Koochin overtly rejected the hospital's definition of death. The couple, relying on traditional notions of cardiopulmonary death, obtained a restraining order to keep Jesse on a ventilator and ultimately removed the brain dead child from the hospital. The ongoing case raises the complex question of whether patients' families should be permitted to opt out of widely accepted definitions of death in favour of their own standards.

The definition of death has evolved rapidly in the United States over the past thirty five years. Until the middle of the twentieth century, the medical community, the legal system, and an overwhelming majority of the public understood death to be synonymous with a cessation of circulation and pulmonary respiration. These attitudes changed as new technologies enabled patients with minimal or no brain function to remain breathing on "life support". ${ }^{2}$ Starting with the efforts of the Harvard Medical School's Ad Hoc Committee to Examine the Definition of Brain Death in 1968, a series of expert panels have sought to redefine death as the irreversible loss of function of the whole brain, including the stem. ${ }^{3}$ Most notable among these was the President's Commission for the Study of Ethical
Problems in Medicine and Biomedical and Behavioral Research, which in 1981 issued a report embracing the whole brain death criterion. This report led to widespread adoption by the states of the Uniform Determination of Death Act-a joint creation of the American Medical Association and the American Bar Association that defines death as either a permanent loss of cardiopulmonary function or whole brain function. Many critics have since argued that this definition is not broad enough: that permanent loss of all higher brain function ("neocortical death") should be the criterion for death. ${ }^{4}$ Most authorities, however-from the American Academy of Neurology to the Catholic Church-accept "whole brain death" as one legitimate definition of death. ${ }^{56}$ In short, a consensus has emerged that "whole brain death" is death.

Although "brain death" has achieved widespread acceptance worldwide, it is not without its critics. ${ }^{7}$ Harvard physicians Robert Truog and Walter Robinson recently wrote in Critical Care Medicine that this definition is a clever fiction used to facilitate organ transplantation. They rejected the concept as "plagued with serious inconsistencies and contradictions" and "fail[ing] to correspond to any coherent biological or philosophical understanding of death". ${ }^{8}$ Outside the United States-most significantly in Japan and Singapore-the approach still faces widespread criticism from the public and the scientific community. ${ }^{9}{ }^{10}$ Strong religious opposition also exists within certain segments of the Buddhist, Native American, and Orthodox Jewish communities. ${ }^{11}$ When New York State adopted the recommendations of a governor's study group that endorsed a "brain death" standard in 1987, they rejected the task force's minority report in which Rabbi J David Bleich of Yeshiva University advocated the exclusive continuation of a cardiopulmonary standard. ${ }^{12}$ The brain death approach has since gained little traction in some ultraOrthodox congregations, which rely on the biblical guidance of Genesis 7:22: "In whose nostrils was the breath of the spirit of life". ${ }^{11}$ The Koochins-Scientologists with a commitment to alternative medicine-reject brain death on both scientific and ethical grounds. ${ }^{13}$

The Koochin case is not the first of its kind. In 1994, the parents of 13 year old Teresa Hamilton-a severe diabetic who fell into a coma-resisted a Florida hospital's efforts to remove their daughter from a ventilator. Three scans showed the girl to have no blood flow to her brain, but her parents insisted her brain was merely "resting". ${ }^{14}$ The hospital and the family eventually reached a widely criticised agreement through which the girl was sent home on a ventilator at the hospital's expense; she suffered a conclusive heart attack four months later. ${ }^{15}$ The Koochin case is, however, bringing more attention to what has been a largely ignored quandary. Currently, statutes in New York and New Jersey permit a patient's family to reject a physician's use of the "brain death" criterion in favour of a cardiopulmonary approach. The other forty eight state legislatures-including Utah-have not yet directly addressed the issue. This is troubling because the stakes are extremely high. Determinations of death have an impact on the distribution of property, the disposition of life and health insurance, and the dissolution of marriages. If some states vest ultimate authority in families whereas others place it in physicians, the prospect exists for a patient to be legally dead in one state while legally alive in another. The ramifications of this patchwork-particularly for the legal system-are truly daunting.

From the Koochins' point of view, what is at stake is nothing less than their autonomous right to make medical decisions for their child. They do not wish to impose a cardiopulmonary death standard upon everyone. Rather, emphasising that there is no universal societal consensus on brain death, they wish to carve out an exception to the general rule in accordance with their own values. The family fully acknowledges that their child's condition is dire. They would prefer, however, to continue to hope and pray until Jesse's heart stops beating. In other words, they want this to be an entirely private, family decision.

Jesse's physicians, in contrast, insist this case (unlike the Quinlan or Schiavo cases) has nothing to do with decisions about how or when to die. Although the boy's heart may continue to beat for weeks or even months on "life support," Jesse-to the hospital's way of thinking-is already dead. His parents are seeking to take home and ventilate a 
corpse-a child as dead as Tony Perkins's mother in Psycho. If the couple believes otherwise, they are in denial. Moreover, carving out an exception for the Koochins may do long term societal damage by undermining the perceived validity of brain death. Organ donation programmes, which rely upon brain dead cadavers, will inevitably have a more difficult time obtaining familial consent. Cost is also a factor: in a society with limited healthcare resources, many question the expenditure necessary to maintain lifeless bodies.

Whether the law should permit individuals to opt out of accepted death standards is a complex and troubling question. It is not one the states can afford to ignore. During the nineteenth century, most state legislatures enacted so called "Enoch Arden laws" to help determine "death" in cases of disappearance, such as sailors missing at sea. Similar action by the states is necessary either to forbid families overtly from opting out of majority death standards or to set rules governing opt out procedures. Jesse's case is bound to repeat itself. It would be highly valuable if the Koochin family's tragedy could bring both public attention and more certainty to this legal grey area.

J Med Ethics 2005;31:641-642.

doi: 10.1136/jme.2005.011718

Correspondence to: Jacob M Appel, Adjunct Assistant Professor, Department of Community Health, Brown University, 140 Claremont Ave \#3D, New York, NY 10027, USA; ima38@ columbia.edu

Received 13 January 2005

Accepted for publication 19 January 2005

\section{REFERENCES}

1 Collins L, Thomson L. Parents remove boy from hospital. Deseret Morning News, 2004 Oct 16, B1

2 Capron AM. Brain death-well settled, yet still unresolved. New Engl J Med 2001;344:1244-6.

3 Ad Hoc Committee of the Harvard Medical School to Examine the Definition of Brain-death. A definition of irreversible coma. JAMA 1968;205:337-40.
4 Smith DR. Legal recognition of neocortical death. 71 Cornell L Rev 850 (May 1986).

5 Rossini E. When life ends. National Catholic Register, 2004 Jun 6, 1

6 The Quality Standards Subcommittee of the American Academy of Neurology. Practice parameters for determining brain death in adults. Neurology 1995:45:1012-14.

7 Wijdicks E. Brain death worldwide: accepted fact but no global consensus in diagnostic criteria. Neurology 2002;58:20-5

8 Truog R, Robinson W. Role of brain death and the dead-donor rule in the ethics of organ transplantation. Critical Care Medicine transplantation. C

9 Anon. Brain death issue still divides nation. The Daily Yomiuri (Tokyo) 2003 Feb 26, 3.

10 Ho A. Brain dead: is it the same as really dead? The Straits Times (Singapore) 2003 Feb 3.

11 Long K. When does life cease: brain-death guidelines at center of debate. Cleveland Plain Dealer, 1999 Oct 3, 1

12 Sullivan R. Failure of brain is legal death New York says. The New York Times, 1987 Jun 19,1

13 Hamilton C. Six year old at center of debate could move to hospice care. Salt Lake Tribune, 2004 Oct 15, Al.

14 Brain dead Florida girl will be sent home on life support. The New York Times, 1994 Feb, 9.

15 Hospital fights parents' wish to keep life support for a "brain dead" child. The New York Times. 1994 Feb 12: sect 1, 6

\section{Reply to: Defining death: when physicians and families differ}

\section{H M Evans}

\section{While there may be a place in some contexts for high handed, "blanket" legislative prohibitions on dissenting views of what constitutes death, the paper under consideration does not describe such a context}

$\mathrm{T}$ his stimulating and provocative paper by Professor Appel, Defining death: when physicians and families differ, asks us to consider (in the context of United States health care where, we are inclined to suppose, autonomy enjoys a primacy among moral considerations) "whether patients' families should be permitted to opt out of widely accepted definitions of death in favour of their own standards". This is a striking question in many ways. It reminds us that, as a simple description of fact, there are indeed different standards for human death in so far as different groups or communities (which can be professional as well as geographical or cultural) have accepted and continue to accept varying notions of what constitutes human death. The question's reference to "opting out" suggests, perhaps reasonably, that it seems prima facie odd to think of adopting a definition of death as being a matter of individual choice. The reference to "permission" invites us to suppose limitations, primarily legal, upon the extent to which such a choice could be tolerated. Also, the question ascribes to certain "definitions of death" (note the plural) the authority of being widely accepted. The definitions thus favoured are, we learn, the various formulations of death referring to the state of the brain, chief among them "whole brain death" although the author is troublingly vague over whether all such formulations are morally, legally, or conceptually equivalent; and the relevant communities of acceptance turn out to consist of manybut, as the author admits, not allphysicians labouring under varying and inconsistent jurisdictions in the United States.

My preface to the criticisms that follow is a welcome for the author's reminding us of the importance and, from time to time, the topicality, of a genuinely philosophical question in technological medical practice. That said, I hold a position substantially different from his, and it is best expressed in terms of my specific disagreements with what he has to say and with what he from time to time implies.

1. The author describes-in what I think are contestable terms-the way the definition of death has evolved in the United States. "Until the middle of the twentieth century", he says, "the medical community, the legal system and an overwhelming majority of the public understood death to be synonymous with a cessation of circulation and pulmonary respiration. These attitudes changed as new technologies enabled patients with minimal or no brain function to remain breathing on 'life support'." This account seems to me to embody an important non sequitur, namely that the maintenance of people lacking brain function should cause us to review a definition of death based on breathing and heartbeat. If people lacking breathing or heartbeat (or both) were maintained on "life support" then this would indeed be striking reason to rethink a definition of death based on those now absent functions. That is not, however, what the author says. The puzzle he presents to us, in the form of people remaining on "life support" with "no brain function" (a state 
of affairs in need of considerably closer description, of course), seems better suited to making us give up a conception of life and death centred upon the brain-the opposite evolutionary direction to the one he detects.

2. The author reviews various kinds of opposition to the "widespread acceptance worldwide" of "brain death", but says most about religiously grounded opposition, and presents the Koochin case in the context of the Koochins' religious beliefs. We must, however, note that one need not hold a particular set of values, religious or otherwise, in order to acknowledge that values are embedded in any conception of death. Our concepts of human death (here I would agree with Pallis, one of the foremost British champions of "brain stem death"1) stand prior to the particular sets of criteria and evidence, including scientific evidence, that express those concepts. Neurological evidence for the satisfaction of the criteria for "brain death" is meaningful only if we have already decided, on other grounds, to regard what the brain does as central to our conception of what is important in human life. Those who think that, for instance, the capacity for consciousness is the key characteristic of human life are expressing an intelligible view, but it arises from a culturally based conception of what is important rather than from what science demonstrates; the science comes later, when one has chosen one's view of human life. Alternative conceptions of the key characteristic of human life are possible; Dawkins shows how one could regard humans as important for being vehicles for their genes (reminding us that not all value systems are religious). ${ }^{2}$ Those basing their support for particular forms of brain centred conceptions of death upon the role of the brain in, say, integrating bodily systems, and/or supporting consciousness, are giving the brain a plausible instrumental role in upholding their chosen key characteristics of human life, as I have elsewhere shown. ${ }^{3}$

3. Conceptual issues are unfortunately admixed with considerations of cost, from time to time, in the paper. For instance, the variety of juridical views among the various state legislatures is "troubling because the stakes are extremely high". The stakes are high of course-they amount to the life and death of a human being-but the author's illustration of the stakes seems to concern other sets of interests: "[T]he girl was sent home on a ventilator at the hospital's expense", and "[d]eterminations of death impact [upon] the distribution of property, the disposition of life and health insurance, and the dissolution of marriages." Now expense and financial hardship are certainly important issues, but these consequences of the patient's life or death are different issues from the question of whether or not the patient actually is still alive. The cost of "life support" may determine how long we can afford it, but it is irrelevant to whether or not the patient on the machine is alive or dead while still connected to it. An unintended conflation, I am sure, but such conflations do little to dispel the sceptic's anxieties that the search for conceptual revision of our notion of death comes from a variety of motives, not all of them wholesome.

4. I share the author's dislike of the "patchwork" of different views in different jurisdictions, but we need to remember that while inconsistency as such is usually a bad thing, it is not as bad as a bad consistency: I would rather a patchwork in which at least some of the relevant legislatures enacted a view of death that I could support than a legal monoculture in which none of them did: so, I take it, would the author.

5. Jesse, we are told, is already dead despite the fact that "the boy's heart may continue to beat for weeks or even months on 'life support"' [my emphasis]. It might appear from this that the author is here considering an essentially upper brain conception of death, a state more usually regarded as irreversible coma and not officially accepted as constituting death in the United Kingdom. The permanent loss of lower brain function would normally be followed readily by loss of bodily integration, systemic collapse and organic dissolution well within such a period of time, although survival for months is possible. Many people remain surprised, however, to learn that even when "brain stem death" ["lower brain death"] criteria are satisfied, the heart may continue to beat spontaneously for some time (hours or days) provided that the blood it pumps is oxygenated by the artificial maintenance of breathing. What a continued spontaneous heartbeat does or does not "count for" in one's conception of human life is a matter of the beliefs and values held by the onlooker. Science can tell us whether or not a heartbeat is spontaneous, and what other physical functions support it or are supported by it, but science cannot tell us what such a heartbeat is worth.

6. It is symptomatic of the author's sense of urgency, perhaps, that he draws on a lurid and I think perverse analogy for the child on a ventilator. Even under his own conception of when one is "already

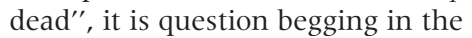
extreme to identify a ventilated patient with a notorious mummified corpse as in: "His parents are seeking to take home and ventilate a corpse-a child as dead as Tony Perkins's mother in Psycho. If the couple believes otherwise, they are in denial." I beg to differ, even though I might agree with the author's unspoken presumption that death is all or nothing, and that there are not degrees of death. One corpse truly is as dead as another corpse. All genuine corpses can legitimately be cremated, for instance: but that in itself shows how cautious we must be in reclassifying a patient as a corpse. A child genuinely "as dead as Tony Perkins's mother" could, from the point of view of the meaning of "death", be cremated in precisely the condition in which she then lay. I think, however, that a parent who doubted the legitimacy of cremating anyone, let alone a child of theirs, in a clinical condition capable of months of "life support", might protest vehemently at having such doubt dismissed as "denial" in the sense the author intends of self imposed delusion (obviously the whole point of the reference to the psychotic Perkins). There is a perfectly respectable sense of "denial", of course, as an active repudiation of what one holds false. The parents are entitled to denial in this sense, and in the case as described I would have every sympathy with them.

7. The same question begging applies to the claim that "carving out an exception for the Koochins may do long term societal damage by undermining the perceived validity of brain death" (here the author relinquishes the quotation marks he previously reserved for the expression "brain death", though 
he does not say why). Those opposed to, for instance, upper brain conceptions of death (as being constituted by irreversible coma) can argue with equal reason that long term societal damage is done by that wholesale revision of the concept of death which legitimises the cremation of still breathing human beings or, in the case of lower brain dead patients, by the cremation of human beings with persistent spontaneous heartbeat. $^{3}$ The long term societal damage the author fears takes, moreover, a somewhat commodified form: "Organ donation programmes, which rely upon brain dead cadavers, will inevitably have a more difficult time obtaining familial consent". Well, perhaps they should have a more difficult time, if they cannot convincingly resist the central charge: namely, that they benefit from the convenience of a revision of the concept of death when that revision falsely purports to rest on purely scientific grounds-as though the concept of death were not (as set out above) prior to the scientific description of the processes identified as relevant to the concept in question.

I would like to end on a note of part agreement with the author. He urges that the different states take action "either to forbid families overtly from opting out of majority death standards or to set rules governing opt out procedures". In the end, death standards ought to command majority assent in a given society; there is something terrible about a situation where they did not. I do not believe that there really is an informed, open eyed, consensus in the USA or in the UK in favour of regarding as dead-and hence crematable (if I may be permitted so uncouth an expression) in precisely that condition-those patients who still breathe or whose heartbeat persists. If, however, there were indeed such a consensus, then, perhaps, fair enough, and not all exceptional views deserve respect: we would not tolerate a parent's wish to keep at home a child who had not yet met their idiosyncratic equation of death with total putrefaction. But this can be addressed in how we govern opt out procedures. Some grounds for opt out will not deserve respect; some will. Pertinently, the Koochins' grounds do, given their child's clinical condition as described in this paper. There may be a place in some contexts for high handed, "blanket" legislative prohibitions on dissenting views. But that context is not here.

J Med Ethics 2005;31:642-644.

doi: 10.1136/jme.2005.011866

Correspondence to: Professor H M Evans, Snow College, University of Durham Queen's

Campus, Thornaby, Stockton on Tees, TS17

6BH, UK; h.m.evans@durham.ac.uk

Received 26 May 2005

Accepted for publication 31 May 2005

\section{REFERENCES}

1 Pallis C, Harley DH. ABC of brain stem death [2nd ed]. London: BMJ Books, 1996

2 Dawkins R. The selfish gene. Oxford: Oxford University Press, 1976.

3 Evans M. Against brain stem death. In: Gillon R, ed. Principles of health care ethics. Chichester: John Wiley \& Sons Ltd, 1994:1041-51.

4 Jonas $\mathrm{H}$. Against the stream: comments on the definition and redefinition of death. Philosophical essays: from ancient creed to technological man. Englewood Cliffs, NJ: Prentice Hall, 1974: 132-40. 